equal aversion points suggest that some durations of pulsed shock may be more aversive than continuous shock, but further work is obviously needed to establish this point.

\section{DISCUSSION}

The finding that a given intensity of footshock is $1 / 10$ th as aversive as an equal intensity of subcutaneous shock was both predictable and surprising. At an intuitive level it is easy to view the application of shock to tender unprotected subcutaneous tissue as likely to be excruciatingly painful. Yet receptors in the skin are oriented toward the external surface, suggesting that painful stimulation applied below the skin should not be as effective as one at its surface. Another factor that may contribute to the painfulness of footshock is that as the animal moves about on the grid he makes and breaks contact with the electrodes, causing variations in current density, which may increase painfulness of the stimulus (Campbell \& Masterson, 1969).

The change in slope of the equal aversion function between .57 and $.80 \mathrm{~mA}$ of footshock probably reflects tissue-damaging electrocautery, receptor-cell hyperpolarization, and/or muscular tetanization, conditions that either reduce or make the animal unable to respond to painful stimulation. What is particulary striking about these intense, sometimes lethal, levels of subcutaneous shock is that they are less aversive, as judged by preference, than intensities of footshock far below a physically damaging level.

In view of the lengthy surgery, expense, poor recovery rate, and high amounts of current needed, subcutaneous shock is clearly not suitable for general use. It may, however, be useful for special purposes, such as comparing spatial and temporal interaction of painful stimuli (cf. Messing \& Campbell, in press).

\section{REFERENCES}

APPEL, J. B. Drugs and escape behavior. Report on Research Grant MH 07239 submitted to National Institute of Mental Health, 1965.

BARFIELD, R. J., \& SACHS, B. J. Sexual behavior: Stimulation by painful electrical shock to skin in male rats. Science, 1968, 161, 392-395.

CAMPBELL, B. A., \& MASTERSON, F. A Psychophysics of punishment. In B. A. Campbell and R. M. Church (Eds.)
Punishment and aversive behovior. New York: Appleton-Century-Crofts, 1969. Pp. 3-42.

HAKE, D. F., \& AZRIN, N. H. An apparatus for delivering pain-shock to monkeys. Journal of the Experimental Analysis of Behavior, 1963, 6, 297.

HUTCHINSON, R. R., AZRIN, N. H., \& HAKE, D. F. An automatic method for the study of aggression in squirrel monkeys. Joumal of the Experimental Analysis of Behavior, 1966, 9. 233-237.

KELLY, N. D., \& GLUSMAN, M. Aversive thresholds for subcutaneous electrical stimulation in the cat. Psychonomic Science, 1964, 1, 207-208.

MESSING, R. B., \& CAMPBELL, B. A. Summation of pain produced in different anatomical regions. Perception \& Psychophysics, in press.

VALENSTEIN, E. S. A note on anesthetizing rat and guinea pigs. Journal of the Experimental Analysis of Behavior, 1961, 4, 6 .

WEISS, J. A tail electrode for restrained rats, Journal of the Experimental Analysis of Behavior, 1967, 10, 85-86.

\section{NOTES}

1. This research was supported in part by NSF Grant GB 8046 .

2. Requests for reprints should be sent to Byron A. Campbell, Department of Psychology, Green Hall, Princeton University, Princeton, N.J. 08540 .

3. Now at Nebraska Psychiatric Institute, Nebraska College of Medicine, Omaha, Nebraska 68105 .

\title{
A constant-current shock source for providing direct or alternating current output ${ }^{1}$
}

ROBERT A. STEWART ${ }^{2}$ and SAM L CAMPBELL ${ }^{3}$ CALIFORNIA STATE COLLEGE AT LOS ANGELES, College Drive, Los Angeles, California 90032

A vacuum-tube constant-current shock source, providing ac, smooth $d c$, and pulsating dc output is described. In addition to output flexibility, the shock source is compact, inexpensive to construct, and has undergone 4 years of testing and laboratory use. Operating instructions, theory of operation, and suggested modifications are included along with performance specifications.

Electric shock is the most frequently used noxious stimulus in psychological research, but it is also one of the least standardized experimental variables. Ss have been shocked with smooth $\mathrm{dc}$, pulsating dc, mono- and biphasic square waves, and currents with irregular waveforms. Because of this plethora of shocking currents, the three-mode shock source described in this paper was developed.
The shock source provides three constant current outputs: $60-\mathrm{Hz}$ ac, $120-\mathrm{Hz}$ pulsating $\mathrm{dc}$, and smooth dc. The term constant current, when applied to constantly changing waveforms (ac and pulsating dc), means generally that successive cycles have identical average and instantaneous current values. Other design aims were high circuit efficiency and simplicity, which contribute materially to reliability, compactness, and low cost. The three-mode shock source requires only 19 electronic components and costs less than $\$ 40$, including a current monitoring meter.

\section{PERFORMANCE SPECIFICATIONS}

The performance of the shock source is a function of the mode of operation, the level of output current, and the resistance of the S. Except for waveform, the electrical specifications of the ac and pulsating dc outputs are identical. In these modes, an increase in load resistance ( $S$ resistance) from 0 to $50,000 \mathrm{ohms}$ results in the following decrements in output current: $1.0 \%$ at $1 \mathrm{~mA}, 1.5 \%$ at $2 \mathrm{~mA}$, $2.0 \%$ at $3 \mathrm{~mA}, 5.0 \%$ at $4 \mathrm{~mA}, 12.0 \%$ at
$5 \mathrm{~mA}$, and $19.0 \%$ at $6 \mathrm{~mA}$. The smooth dc mode is the most efficient. The filter capacitors charge to the peak voltage of the power transformers, and the peak current is equal to the average output current. In the smooth dc mode, a 50,000-ohm increase in $\mathrm{S}$ resistance causes the following current decrements: $0.5 \%$ at $1 \mathrm{~mA}, 1.0 \%$ at $2.3 \mathrm{~mA}, 2.0 \%$ at $4 \mathrm{~mA}, 4.0 \%$ at $5 \mathrm{~mA}$, and $6.0 \%$ at $6 \mathrm{~mA}$.

The output voltage of a constant-current shock source is a function of the selected current level and the resistance of a given S. However, the open-circuit (no load) output voltage is known and allows, by Ohm's law, the calculation of the maximum $S$ resistance through which a desired current can be maintained. The effective voltage (RMS) for the ac and pulsating dc modes is $250 \mathrm{~V}$; the open-circuit output voltage in the smooth dc mode is $350 \mathrm{~V}$. The latter voltage exceeds the design-maximum plate voltage of the 6AU6 vacuum tube (RCA, 1965), but in the past 4 years no tube has failed catastrophically, nor has tube life been short. 


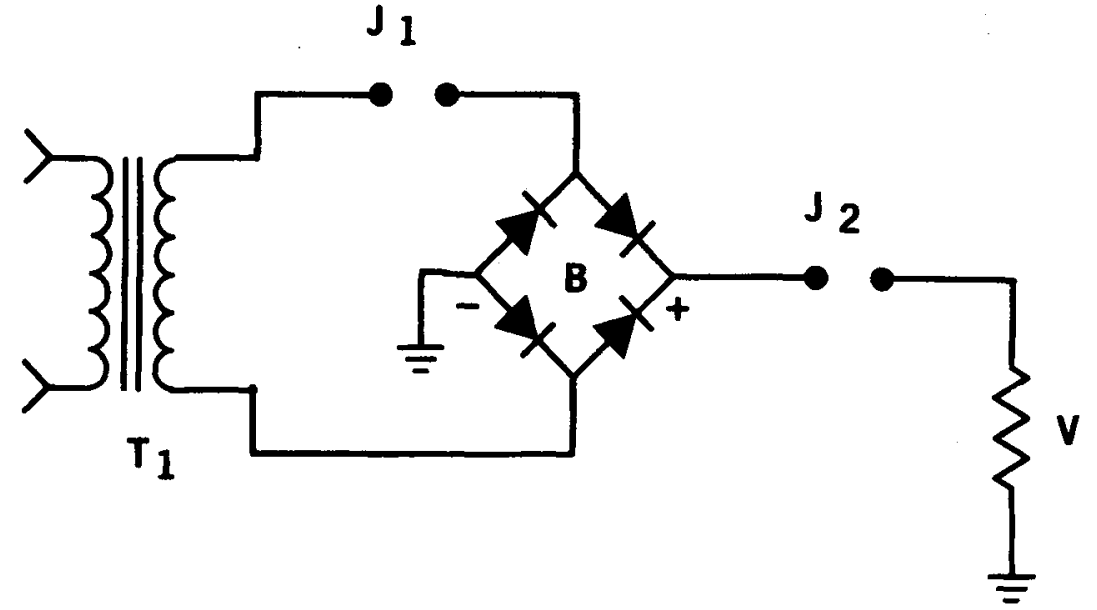

Fig. 1. Simplified diagram of the three-mode shock source.

The three-mode shock source has been used in studies requiring that specific shock levels be maintained for 24 to $48 \mathrm{~h}$ (Miller, Stewart, \& Kiker, 1968; Miller, Stewart, Watson, \& Kiker, 1969); drift of $1 \%$ or less was observed. Neither study required shock in excess of $1 \mathrm{~mA}$, and at higher current levels drift may be a function of ambient temperature, due to the temperature coefficient of the level-setting potentiometer. The shock source has been used for periods up to $20 \mathrm{~min}$ at the 4- to 5-mA level with no observable drift (Stewart, Groff, \& Kiker, 1968).

In summary, the current regulation and stability of the three-mode shock source is

Fig. 2. Functional schematic and parts list for the three-mode shock source:

C-10 and 30 Mfd 450-V electrolytic capacitor (Aerovox AEP 62J or Sprague 1705 and 1711).

D-Diodes, all diodes are 1 N1696.

F-Fuse (Bussman AGC $1 / 4 \mathrm{~A}$ ) and fuseholder (Bussman HKP).

$J_{1}-J_{2}-5$-way binding post pairs (Superior Electric DF 30-2),

M-5-mA milliammeter (or microammeter, see text).

$\mathbf{R}_{1} \cdot \dot{R}_{2}-100-o h m, 1 / 2-W$ carbon resistor (10\%).

$R_{3}-82,000-o h m, 2-W$ carbon resistor (10\%).

$R_{4}-100,000$ ohm potentiometer (Ohmite CMU 1041).

$S_{1}-$ S.P.S.T. toggle switch (Cutler-Hammer 7580K6).

$S_{2}-$ D.P.S.T. momentary contact pushbutton switch (Switchcraft FF-1004).

$S_{3}$-D.P.S.T. toggle switch (Cutler-Hammer 7590K6).

$\mathrm{T}_{1}-\mathrm{T}_{2}-$ Power transformer, $500 \mathrm{~V} \mathrm{CT}$ $(250-0-250)$ at $15 \mathrm{~mA}$ and $6.3 \mathrm{~V}$ ac at $1 \mathrm{~A}$ (Thordarson $24 R 89$ or Triad R-4A).

$\mathrm{V}-6 \mathrm{AU}$ 6A vacuum tube. adequate to $4-5 \mathrm{~mA}$ in the smooth $\mathrm{dc}$ mode and 3-4 $\mathrm{mA}$ in the other two modes for up to $48 \mathrm{~h}$. These levels and time parameters have been found adequate for research with rats (Stewart \& Kiker, 1968; Stewart et al, 1969) and humans ${ }^{4}$ (Stewart, Groff, \& Kiker, 1968; Dawson \& Nation $^{5}$; Dawson \& Reardon ${ }^{5}$ ).

\section{CIRCUIT DESCRIPTION}

Circuit function can be most easily discerned in the simplified circuit presented in Fig. 1. In this diagram the 6AU6 regulator tube (V in Fig. 2) has been replaced by its functional equivalent, a resistor (V), and other circuits not essential to current regulation have been omitted. In essence, the entire load of the power transformer $\left(\mathrm{T}_{1}\right)$ consists of two resistances: the effective resistance of the regulator tube (V) and the resistance of the $S$ (skin and tissue resistance). Ss can be connected to the shock source at one of two points: Jack $1\left(\mathrm{~J}_{1}\right)$ for ac shock or Jack $2\left(\mathrm{~J}_{2}\right)$ for dc shock, with the unused jack being shorted out. While the relationship is obscured by the bridge rectifier (B), the circuit is a simple series configuration; the resistance at $J_{1}$ or $J_{2}$ is in series with the regulator tube (V). Since the current is equal at all points in a series circuit, the same degree of regulation is imposed on the ac, before rectification, as on the rectified dc. To maintain the identity between the unrectified ac and the $\mathrm{dc}$, no additional power is drawn from the secondary of the power transformer $\left(T_{1}\right)$.

The functional diagram of the shock source is shown in Fig. 2. The basic regulator circuit is an adaptation of a shock source described by Mount and Lehner (1948). Because it was impossible to obtain screen grid power from the plate power transformer $\left(T_{1}\right)$, a separate screen grid power supply was required. This circuit is composed of a screen grid power transformer $\left(\mathrm{T}_{2}\right)$, a full-wave rectifier (two diodes), a surge-limiting resistor $\left(\mathbf{R}_{2}\right)$, and a screen resistor $\left(\mathbf{R}_{\mathbf{3}}\right)$ to limit screen-grid dissipation. A dual-section electrolytic capacitor (C) can be switched (via $\mathrm{S}_{3}$ ) into the screen and plate circuits, filtering the power supplies and providing smooth $\mathrm{dc}$ shock current $\left(\mathrm{J}_{2}\right)$. Omitting these components, the functional circuit is almost reduced to the basic circuit of Fig. 1.

The regulating action of the circuit has been described by Mount and Lehner (1948) but will be reviewed briefly here. The total current output of the plate power transformer $\left(T_{1}\right)$ passes through the 6AU6 regulator tube $(V)$ and its variable cathode resistor $\left(R_{4}\right)$, which is also the current level control. The voltage drop developed across $R_{4}$ constitutes the grid bias of the 6AU6 regulator tube. Once a bias level is established by manually adjusting $\mathbf{R}_{4}$ (which also sets the output level), any additional or later change in

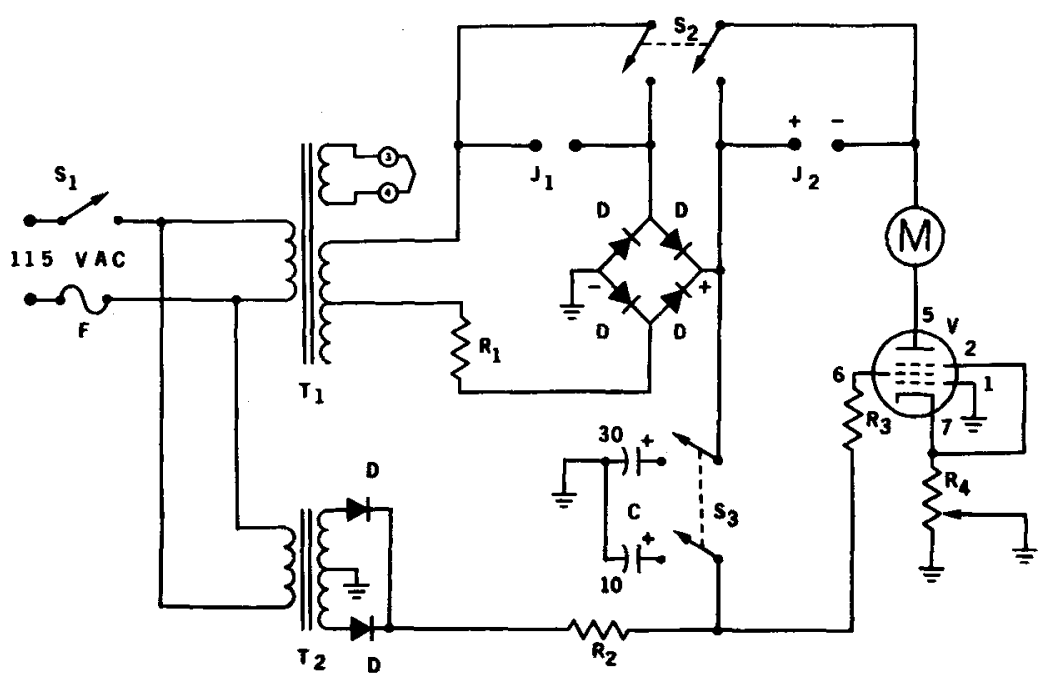


cathode current causes the effective resistance of the tube to change, tending to return the current to its original level. Thus, the variable cathode resistor $\left(R_{4}\right)$ functions as an "error detector" and as the current level control.

The remaining components consist of a power switch $\left(S_{1}\right)$, a line fuse $(F)$, a switch $\left(S_{2}\right)$ to enable level setting, a current-monitoring meter $(\mathrm{M})$, and a plate circuit surge-limiting resistor $\left(R_{1}\right)$. Both surge-limiting resistors $\left(R_{1}\right.$ and $\left.R_{2}\right)$ protect the secondaries of the power transformers $\left(T_{1}\right.$ and $\left.T_{2}\right)$ when the filter capacitor $(C)$ is switched into the circuit. If higher current transformers are substituted, these resistors can be omitted. The meter (M) can be either a milliammeter or a microammeter with switched shunt resistors, depending on anticipated current levels. If the latter arrangement is used, the switch must be of the make-before-break (shorting) type, so the meter is not returned to maximum sensitivity during range change. Normally, shock will be programmed by contacts external to the shock source, and these contacts will represent an open circuit, except during shock presentation. Thus, it is necessary to short circuit both output jacks $\left(J_{1}\right.$ and $\left.J_{2}\right)$ while adjusting the level of output current. The simultaneous short circuit of both jacks is accomplished by depressing $S_{2}$. If fairly constant $S$ resistances are anticipated, resistors approximating these values can be connected in series with each section of $S_{2}$. These resistors will give a better approximation of output current at high levels.

\section{OPERATION AND CONSTRUCTION}

Output current adjustment is quite simple; the output level control $\left(R_{4}\right)$ is set for minimum current, and the appropriate meter range selected, then the current setting switch $\left(S_{2}\right)$ is depressed, and the output current increased, via $R_{4}$, until the desired level is reached. The current level can be checked by depressing $S_{2}$ whenever shock is not being presented.

The multimode output of the shock source results in several interesting phenomena. For a given setting of $\mathrm{R}_{4}$, the ac and pulsating dc output currents are the same, but switching to the smooth $\mathrm{dc}$ mode will increase the output current with $\mathbf{R}_{4}$ being unchanged. Further, stray capacity in the wiring external to the shock source may result in a significant leakage current during ac operation. If a sensitive meter (M) is used, this may result in an appreciable reading between shocks. Last, ac output cannot be used when $S_{3}$ is in the smooth dc position; when the filter capacitor (C) is in the circuit, the output at $J_{1}$ has a pulsed waveform and is unregulated.

One primary caution must be observed in constructing the shock source. The six ground connections shown in Fig. 2 must be well insulated from the chassis and returned to a common tiepoint. If this is not done, all conductors attached to the output jacks, including Ss, will be $350 \mathrm{~V}$ above ground potential.

When the shock source has been properly constructed, with all electrical components and the six ground-tie points well insulated from the chassis, human and animal Ss may be "grounded" to a common external ground interconnecting all the research apparatus used in the experiment. The advantages of S grounding are twofold: It is safer because a circuit failure is less likely to cause a dangerous shock, and $S$ grounding reduces the noise introduced while recording GSR or other physiological signals requiring high amplification. If none of the circuit components are electrically connected to the chassis, then either side of $J_{1}$ or $J_{2}$ can be connected to the common ground point of the other apparatus in the research system, grounding the $\mathrm{S}$. However, $\mathrm{J}_{1}$ and $\mathrm{J}_{2}$ cannot be connected to the chassis simultaneously, and the connection used to ground them must be moved if the output is moved from one jack to the other.

The relationship between output current and the value of $R_{4}$ is not linear; at high output levels a small change in the value of $\mathbf{R}_{\mathbf{4}}$ results in a large change in output current. To facilitate operation at high current levels, a 10-turn potentiometer may be used in place of $R_{4}$ or a low resistance $(2-5 \mathrm{~K})$ vernier potentiometer may be placed in series with $\mathbf{R}_{\mathbf{4}}$.

While the shock source was designed for 50 - to $60-\mathrm{Hz}$ operation, the frequency of operation can be extended into higher frequencies by using other power transformers. If high frequency operation is anticipated, it will be necessary to keep the plate and screen voltage in phase and to obtain filament power from a separate transformer.

\section{REFERENCES}

MILLER, A. R., STEWART, R. A., \& KIKER, V. L. The facilitative effects of shock and sensory deprivation on bar-pressing during extinction. Psychonomic Science, 1968, 10, 113-114.

MILLER, A. R., STEWART, R. A., WATSON, R. A. R., \& KIKER, V. L. Facilitative effects of shock on bar-pressing. Psychonomic Science, 1969, 14, 21-22.

MOUNT, G. E., \& LEHNER, G. F. The use of certain electronic tubes in the psychological laboratory. American Journal of Psychology, 1948, 61, 247-258.

RADIO CORPORATION OF AMERICA. RCA receiving tube manual. Harrison, N.J: Radio Corporation of America, 1965.

STEWART, R. A., \& KIKER, V. L. The effect of conflict on delayed response performance. Paper read at the meetings of the Western Psychological Association, San Diego, March 1968.

STEWART, R. A., GROFF, C., \& KIKER, V.L. The modification of critical flicker fusion threshold (CFF) by experimentally induced anxiety. Paper read at the meetings of the Western Psychological Association, San Dicgo, March 1968.

STEWART, R. A., KIKER, V. L., STEELE, R. E., MILLER, A. R., \& WILSON, W. The role of spatial facotrs in avoidance acquisition. Paper read at the meetings of the Western Psychological Association, Vancouver, June 1969.

\section{NOTES}

1. The development of this circuit was supported in part by Analytic Behavioral Systems Grant E-2001. Reprint requests should be addressed to Richard E. Steele, Department of Psychology, Marymount College, 7750 Fordham Road, Los Angeles, California 90045.

2. Now at the Tel-Gard Corp., Los Angeles, Catifornia.

3. Now at Texas Technological College, Lubbock, Texas.

4. To protect human Ss, a low-current instrument fuse (Littelfuse 8AG-10 mA) should be included in both sides of the $S$ circuit.

5. Unpublished studies, California State College at Los Angeles, 1968. 